\title{
Optimization of clinical outcome of women with previous one lower segment cesarean section
}

\author{
Mamdoh Eskandar $^{1 *}$, Jameelah Aboud ${ }^{2}$, Majed Alshahrani ${ }^{2}$, Mervat Hassanein $^{3}$, Azza Alyamani $^{1}$ \\ ${ }^{1}$ Department of Obstetrics and Gynecology and Reproductive Medicine, College of Medicine, King Khalid University, Abha, KSA \\ ${ }^{2}$ Department of Obstetrics and Gynecology, Abha General Hospital, Abha, KSA \\ ${ }^{3}$ Department of Family and Community Medicine, College of Medicine, King Khalid University, Abha, KSA \\ Email: * mamdoheskandar@hotmail.com
}

Received 16 May 2012; revised 17 June 2012; accepted 29 June 2012 Cesarean (VBAC) in comparison to Repeat Cesarean Section (RCS) and to those undergoing vaginal birth. Design and Settings: Retrospective study, women with a history of one lower segment cesarean section (LSCS) admitted to Abha General Hospital for delivery from September, 2010 to February, 2011. Subjects and Methods: The demographic maternal and neonatal data and data concerning the course of delivery were reviewed in $\mathbf{4 1 8}$ women underwent trial of labor (TOL) and subjected to statistical analysis to study the predictive factors and outcome. All cases were divided into 3 groups, VBAC group (212 women), RCS group (206 women) and the neonates of the VBAC group were compared to those of a control group consists of 287 neonates who were delivered vaginally. Results: The success rate of VBAC was $50.72 \%$, with no uterine rupture or wound dehiscence. Failure to progress was the most common $(\mathbf{4 0 . 2 \% )}$ indication of RCS followed by fetal distress $(29.9 \%)$. Young maternal age $(P<0.05)$, previous vaginal deliveries after CS $(\mathrm{P}<0.05)$ and occiput anterior position $(P<0.01)$ were significantly associated with successful VBAC. Neonatal Intensive Care Unit (NICU) admission was significantly higher in the RCS group $(P<0.001)$, while no significant difference was found between NICU admission in the VBAC and the control groups. Conclusion: VBAC should remain an available option. Informed consent, good reporting and thorough documentation of the VBAC decision are crucial. During TOL, continuous fetal monitoring and, ultrasound evaluation of the previous scar are recommended. Emergency CS should be considered if duration of the TOL is prolonged with non reassuring CTG.

\footnotetext{
"Corresponding author.
}

Keywords: VBAC; TOL; RCS; Pregnancy Outcome

\section{INTRODUCTION}

Quality improvement efforts, practice management skills, in addition to safe, ethical practices and the need for a focus on prevention are all necessary to optimize clinical outcomes. Change based on adoption of national standards derived from Evidence-Based practice and randomized controlled trials (RCTs) alone may not always establish how diagnostic and therapeutic procedures actually work in clinical practice. For this reason, health care organizations must develop the tools to identify and adopt best practice and improve clinical outcomes locally [1].

Previous studies assessing the safety of VBAC have compared VBAC to Elective Repeat Cesarean Section (ERCS) despite the fact that the risks posed by each are considerably different. Explaining the complications of VBAC in a way that is meaningful to women can be challenging and thus a comparison to a similar group of women who have undergone normal vaginal delivery may be a more relevant comparison [2].

Benefits of VBAC may outweigh the risks in most women with one previous low transverse cesarean, but even with good facilities and personnel, numerous factors warrant special caution. Therefore, the aim of this study was to investigate the outcome in women with planned Vaginal Birth After Caesarean (VBAC) in comparison to Repeat Cesarean Section (RCS) and also to those undergoing vaginal birth, in attempt to build up a safer clinical pathway for management and improve the health-care delivery system in Abha General Hospital in the coming years.

\section{SUBJECTS AND METHODS}

This retrospective study was conducted on a total of 418 women with a history of one lower segment cesarean section (LSCS) and had delivered at Abha General Hospital from September, 2010 to February, 2011.

The demographic maternal and neonatal data as well 
as data concerning the course of the trial of labor of all cases were reviewed using especially designed data collecting tables, which then subjected to statistical analysis. Accordingly; all cases were divided into 3 groups; VBAC group consists of 212 women, RCS group consists of 206 women, (50/212 in the VBAC and 84/206 in the RCS groups respectively were of high parity and analyzed separately) and a control group consists of 287 neonates who were delivered by spontaneous vaginal delivery. The neonates of the VBAC group were compared to those of the control group who their mothers delivered vaginally matched for age and parity. Descriptive statistics included mean and standard deviation. $t$ test as well as Chi Square test were the significance tests that used. $\mathrm{P}$ value $<0.05$ indicated significance.

\section{RESULTS}

The demographic maternal data of all women participating in the study were presented in Table 1.

212/418 (50.72\%) delivered by VBAC while 206/418 (49.28\%) delivered by RCS after a failed trial of labor, with no uterine rupture or wound dehiscence. Maternal age was significantly older in RCS group with significant higher percentage of obstetric complications $(\mathrm{P}<0.05)$.

Failure to progress was the most common (40.2\%) indication of RCS followed by fetal distress (29.9\%), re- fusal of the patients to continue the trial (2.5\%), impending rupture of the uterus and intrapartum spotting (2.1\%), while other indications as abnormal head position, IUGR, prolonged ROM, accounted for about fourth of the cases (25.3\%).

Significant higher percentage (35.19\% vs. 17.21\%) of successful VBAC was found in women of low parity who had previous vaginal deliveries after CS (Table 2). In all women either of low or high parity postpartum complications were highly significant in those delivered by RCS (Tables 3 and $\mathbf{4}$ ).

The occiput anterior was highly significant position in women who delivered vaginally by successful VBAC than RCS (98.15\% vs. 87.70\% respectively). Apgar score $<5$ at one minute was significantly $(\mathrm{P}<0.001)$ more among the neonates of women who delivered by RCS (17.36\% vs. $1.25 \%$ respectively) Table 5.

The comparison between the percentages of NICU admission in VBAC and RCS groups (5.56\% vs. 19.67\% respectively) being higher in the RCS group was presented in Table 5 while no significant difference was found between the percentages of NICU admission in the VBAC and the control groups.

\section{DISCUSSION}

Based on current evidence, the success rates for VBAC

Table 1. Demographic maternal data.

\begin{tabular}{|c|c|c|c|}
\hline & VBAC Group N = 212 & RCS Group N = 206 & P Value \\
\hline Age (Years) Mean (SD) ${ }^{a}$ & $29.65(5.584)$ & 31.35 (6.507) & $\mathrm{P}<0.05$ \\
\hline $\begin{array}{c}\text { Social Class } \\
\text { Number (Percent) } \\
\text { Low } \\
\text { Moderate }\end{array}$ & $\begin{array}{c}\mathrm{N}=207^{\mathrm{c}} \\
42(19.81 \%) \\
165(77.83 \%)\end{array}$ & $\begin{array}{c}\mathrm{N}=203^{\mathrm{d}} \\
44(21.67 \%) \\
159(78.33 \%)\end{array}$ & $P>0.05$ \\
\hline $\begin{array}{c}\text { Previous History of Associated Medical Disorders } \\
\text { Number (Percent) }\end{array}$ & $5(2.02 \%)$ & $9(2.90 \%)$ & $\mathrm{P}>0.05$ \\
\hline $\begin{array}{l}\text { Associated Obstetric Complications } \\
\text { Number (Percent) }\end{array}$ & $37(13.03 \%)$ & $62(29.95 \%)$ & $\mathrm{P}<0.05$ \\
\hline
\end{tabular}

${ }^{\mathrm{a}}$ Values are mean age (standard deviation); ${ }^{\mathrm{b}}$ Number (percent); ${ }^{\mathrm{c}} 5$ cases were missed; ${ }^{\mathrm{d}} 3$ cases were missed.

Table 2. Clinical characteristics of the previous CS in women of low parity.

\begin{tabular}{ccc}
\hline & VBAC Group N = 162 & RCS Group N = 122 \\
Interval since PCS ${ }^{\mathrm{e}}$ (Months) Mean (SD) & $38.674(25.856)$ & $40.818(30.531)$ \\
Previous vaginal delivery after PCS Number (Percent) & $57(35.19 \%)$ & $21(17.21 \%)$ \\
Postoperative Complications after PCS & None & None \\
Hospital Stay after PCS (Days) Mean (SD) & $3.476(0.859)$ (Range 2 - 4) & $3.458(0.798)($ Range 3 - 5) \\
\hline
\end{tabular}

${ }^{\mathrm{e}}$ Previous cesarean section. 
Table 3. Course of delivery in the VBAC and RCS groups in women of low parity.

\begin{tabular}{cccc}
\hline & VBAC Group N = 162 & RCS Group N = 122 & P Value \\
\hline Gestational Age (Weeks) Mean (SD) & $39.287(1.393)$ & $38.964(2.427)$ & $\mathrm{P}>0.05$ \\
Attendant Number (Percent) & & & \\
Resident & & $61(50 \%)$ & $\mathrm{P}<0.001$ \\
Specialist & $146(90.12 \%)$ & $61(50 \%)$ & $\mathrm{P}>0.05$ \\
Oxytocin Units Number (Percent) 2 Units+ & $16(9.88 \%)$ & $14(11.48 \%)$ & $\mathrm{P}>0.05$ \\
Duration of Labor (Hours) Mean (SD) & $12(7.41 \%)$ & $9.346(7.969)$ & $19(9.22 \%)$ \\
Maternal Postpartum Complications ${ }^{\mathbf{f}}$ Number (Percent) & $7.531(6.479)$ & $\mathrm{P}<0.001$ \\
\hline
\end{tabular}

${ }^{\mathrm{f}}$ Postpartum complications include; hemorrhage, maternal ICU admission and emergency blood transfusion.

Table 4. Course of delivery in the VBAC and RCS groups in women with high parity.

\begin{tabular}{cccc}
\hline & VBAC Group N = 50 & RCS Group N = 84 & P Value \\
\hline Gestational Age (Weeks) Mean (SD) & $39.519(1.221)$ & $38.741(2.123)$ & $\mathrm{P}>0.05$ \\
Attendant Number (Percent) \\
$\begin{array}{c}\text { Resident } \\
\text { Specialist }\end{array}$ & $43(86 \%)$ & $31(37.65 \%)$ & $\mathrm{P}<0.05$ \\
Oxytocin Units Number (Percent) 2 Units+ & $7(14 \%)$ & $53(62.35 \%)$ & $\mathrm{P}>0.05$ \\
Duration of Labor (Hours) Mean (SD) & $3(6 \%)$ & $11.919(8.949)$ & $\mathrm{P}<0.05$ \\
Maternal Postpartum Complications Number (Percent) & $7.25(7.302)$ & $4(1.94 \%)$ & $\mathrm{P}<0.001$ \\
\hline
\end{tabular}

Table 5. Clinical data of the neonates in the VBAC and RCS groups in women of low parity.

\begin{tabular}{|c|c|c|c|}
\hline & VBAC Group N = 162 & RCS Group N =122 & P Value \\
\hline \multicolumn{4}{|l|}{ Gender Number (Percent) } \\
\hline Males & $74(45.68 \%)$ & 68 (55.74\%) & $\mathrm{P}<0.001$ \\
\hline Females & $88(54.34 \%)$ & $54(44.26 \%)$ & \\
\hline Birth Weight (Grams) Mean (SD) & $2996(0.452)$ & $3011(0.432)$ & $\mathrm{P}>0.05$ \\
\hline Placental Weight (Grams) Mean (SD) & $561.132(116.327)$ & $623.623(155.077)$ & $\mathrm{P}<0.01$ \\
\hline \multicolumn{4}{|l|}{ Presentation Number (Percent) } \\
\hline Occiput Anterior & $159(98,15 \%)$ & 107 (87.70\%) & $\mathrm{P}<0.01$ \\
\hline Occiput Posterior & $3(1.85 \%)$ & $15(12.30 \%)$ & \\
\hline Apgar Score at 1 Minute Number (Percent) & $\mathrm{N}=160^{\mathrm{g}}$ & $\mathrm{N}=121^{\mathrm{h}}$ & \\
\hline$<5$ & $2(1.25 \%)$ & $21(17.36 \%)$ & $\mathrm{P}<0.001$ \\
\hline $5+$ & $158^{8}(98.75 \%)$ & $100^{\mathrm{h}}(82.64 \%)$ & \\
\hline NICU Admission Number (Percent) & $9(5.56 \%)$ & $24(19.67 \%)$ & $\mathrm{P}<0.001$ \\
\hline
\end{tabular}

$\mathrm{g}_{2}$ cases were missed; ${ }^{\mathrm{h}} 1$ case was missed.

range from 60\% - 80\% (American College of Obstetricians and Gynecologists (ACOG) VBAC Guidelines) [3]. Decision analysis concluded that VBAC is a reasonable option when the chance of success exceeds 50\% [4].

Failure to progress was the most common (40.2\%) indication of RCS in this study, followed by fetal distress (29.9\%). This is in contradictory to Finley and Gibbs who found that true fetal distress only occurs in $1.5 \%$ of all VBAC attempts [5]. This is may be due to misinterpretation of CTG traces, therefore, further evaluation of the relationship between fetal tracing abnormalities and uterine rupture is important as a nonreassuring fetal heart rate is the most frequent sign [6].

Uterine rupture is more likely during trial of labor but the rate is usually $<1 \%(0.4 \%-0.9 \%)$. It is more likely with shorter interval between pregnancies $<18$ months [7], with labor induction or oxytocin augmentation [8], macrocosmic babies [9] and postdates pregnancies [10].

In the present study, no uterine rupture or wound dehiscence were reported in the studied sample. This agreed with one study reported $0.0 \%$ rupture range without use of oxytocin [11] and other study reported 
rare uterine rupture $(0.15 \%)$ when labor was spontaneous without augmentation [12]. The reasonable explanation is that the interval since the Previous Cesarean Section (PCS) in the present study was long (Table 2), our patients came in spontaneous labor and augmentation with Oxytocin was used in small dose only in $7.4 \%-11.5 \%$ of patients (Table 3). Also we have no postdates (Table 4) or macrosomia (Table 5).

Studying the course of delivery in the previous CS in VBAC group compared to RCS group, results revealed significant higher percentage of vaginal deliveries after the PCS in the VBAC compared to RCS group (Table 2). This is in agreement of previous studies which proved that women who have delivered vaginally are more likely to succeed at VBAC by factor of 9 to 28 than those who have not $[13,14]$.

Despite thousands of citations in the world's literature there are currently no randomized trials comparing maternal or neonatal outcomes for both RCS and VBAC. In the current study maternal complications (postpartum hemorrhage, emergency blood transfusion and maternal Intensive Care Unit admissions) were significantly higher among RCS group compared to VBAC group (Tables 3 and 4). Author et al. and authors $[15,16]$ showed lower maternal morbidity after a trial of labor than after RCS. The same was found in the present research where maternal complications in all women were significantly higher among RCS group compared to VBAC group.

With repeat cesarean section the risk of placental problems is increased and infants are affected. In the present study, no perinatal deaths were recorded in the studied sample, in absolute terms, the risk of perinatal death associated a trial of labor and uterine rupture was low 1 in 2200 [17]. In the present study, we have no perinatal deaths because we have no uterine ruptures. This is supported by the finding of Lydon-Rochelle et al. [8] who found the rate of infant mortality was $5.5 \%$ in cases involving uterine rupture, compared with $0.5 \%$ without rupture.

As found in one study that the rate of infant mortality was 5.5\% in cases involving uterine rupture.

Comparing the neonatal morbidity in VBAC, RCS and control groups, the present study revealed that there was a highly significant difference between percentages of NICU admission in both studied groups; being more in RCS group (Table 5), while no significant difference was found between the VBAC and the control groups. This disagrees with a study which recorded hypoxic-ischemic encephalopathy occurred in no infants in ERCS and in 12 infants in TOL group [18]. This contradiction can be explained by that our women did RCS after failed VBAC thus more exhausted infants needed NICU admission while cesarean sections in their study were planned ERCS.
Based on the results of this research, we conclude that when women are carefully selected in situation with optimal facilities and personnel, VBAC should remain an available option. Informed consent, good reporting and thorough documentation of the VBAC decision are crucial to reduce the medico legal risk. Every woman with history of one LSCS in spontaneous labor, providing there was no clear indication of RECS, should be carefully evaluated by individualized assessment before a management plan is made and documented. All women with full term, singleton, normal pregnancy, with average fetal weight, vertex presentation should have an attempt of VBAC especially in young women with low parity and history of previous vaginal deliveries after their previous CS.

During the Trial of Labor, continuous fetal monitoring is mandatory, ultrasound evaluation of the previous scar is recommended both intrapartum and postpartum to confirm scar integrity and detect asymptomatic incomeplete uterine rupture. Emergency CS should be considered if the duration of the TOL is prolonged with non reassuring CTG. The attending doctor should be fully aware of these General Guidelines for VBAC.

Active role should be played in educating both women and practitioners about healthy childbirth practices that not only encourage VBAC but also discourage the overuse of primary CS. This is of prime importance especially among Saudi women who usually plan for big families.

Further studies are needed to investigate safety of VBAC with twins, suspected macrosomia and unknown uterine scars. Also, to identify the possible hidden perinatal mortality if VBAC is compared to RECS at 37 38 weeks.

\section{REFERENCES}

[1] Hobel, C.J., Lu, M.C. and Gambone, J.C. (2010) A life-course perspective for women's health care. Safe, ethical and effective practice. In: Gambone, J.C. and Hobel, C.J., Eds., Essentials of obstetrics and gynecology, 5th Edition, Elsevier, Philadelphia, 3-11.

[2] Rozen, G., Ugoni, A.M. and Sheehan, P.M. (2010) A new perspective on VBAC: A retrospective cohort study. WWW.PubMed.com

[3] American College of Obstetricians and Gynecologists (2010). VBAC guidelines published in August. http://www.acog.org/

[4] Mankuta, D.D., Leshno, M.M., Menasche, M.M. and Brezis, M.M. (2003) Vaginal birth after CS: Trial of labor or repeat CS. A decision analysis. American Journal of Obstetrics \& Gynecology, 189, 714-719. doi:10.1067/S0002-9378(03)00833-0

[5] Finley, B.E. and Gibbs, C.E. (1986) Emergent cesarean delivery in patients undergoing a trial of labor with a 
transverse lower segment scar. American Journal of $\mathrm{Ob}$ stetrics \& Gynecology, 155, 936-939.

[6] American College of Obstetricians and Gynecologists (2004) Practice bulletin 54: VBAC. Washington DC.

[7] Shipp, T.D., Zelop, C.M., Repke, J.T., Cohen, A., Lieberman, E. (2001) Interdelivery interval and risk of symptomatic uterine rupture. Obstetrics \& Gynecology, 97, 175-177. doi:10.1016/S0029-7844(00)01129-7

[8] Lydon-Rochelle, M., Holt, V.L., Easterling, T.R. and Martin, D.P. (2001) Risk of uterine rupture during labor among women with a prior cesarean delivery. The New England Journal of Medicine, 345, 3-8. doi:10.1056/NEJM200107053450101

[9] Elkousy, M.A., Sammel, M., Stevens, E., Peipert, J.F. and Macones, G. (2003) The effect of birth weight on vaginal birth after cesarean delivery success rates. American Journal of Obstetrics \& Gynecology, 188, 824-830. doi:10.1067/mob.2003.186

[10] Zelop, C.M., Shipp, T.D., Cohen, A., Repke, J.T. and Lieberman, E. (2001) Trial of labor after 40 weeks gestation in women with prior cesarean. Obstetrics \& Gynecology, 97, 391-393. doi:10.1016/S0029-7844(00)01175-3

[11] Chattopadhyay, S.K., et al. (1994) Planned vaginal delivery after two previous cesarean sections. British Journal of Obstetrics and Gynaecology, 101, 498-500.

[12] Dekker, G.A., Chan, A., Luke, C.G., Priest, K., Riley, M., Halliday, J., King, J.F., Gee, V., O’Neill, M., Snell, M., Cull, V. and Cornes, S. (2010) Risk of uterine rupture in
Australian women attempting vaginal birth after one prior caesarean section: A retrospective population-based cohort study. An International Journal of Obstetrics \& Gynaecology, 117, 1358-1365. doi:10.1111/j.1471-0528.2010.02688.x

[13] Flamm, B.L. (1997) Once a cesarean always a controversy. Obstetrics \& Gynecology, 90, 312-315. doi:10.1016/S0029-7844(97)00263-9

[14] McNally, O.M. and Tumer, M.J. (1999) Induction of labor after one previous cesarean section. Australian and New Zealand Journal of Obstetrics and Gynaecology, 39, 425-429. doi:10.1111/j.1479-828X.1999.tb03126.X

[15] Rosen, M.G., Dickinson, J.C. and Westhoff, C.L. (1991) Vaginal birth after cesarean: A meta-analysis of mortality and mortality. Obstetrics \& Gynecology, 77, 465-470.

[16] O’Brien, J.M., Barton, J.R. and Donaldson, E.S. (1996) The management of placenta percreta conservative and operative strategies. American Journal of Obstetrics \& Gynecology, 175, 1632-1638.

[17] Smith, G.C., Pell, J.P., Cameron, A.D. and Dobbie, R. (2002) Risk of perinatal death associated with labor after previous cesarean delivery in uncomplicated term pregnancies. The Journal of the American Medical Association, 287, 2684-2690. doi:10.1001/jama.287.20.2684

[18] Mark, B., Landon, M.D., John, C., Hauth, M.D., Kenneth, J., et al. (2004) Maternal and perinatal outcomes associated with a trial of labor after cesarean delivery. The New England Journal of Medicine, 351, 2581-2589. doi:10.1056/NEJMoa040405 